\title{
Facebook, The New Edutainment Avenue in TVET for Affective Learning
}

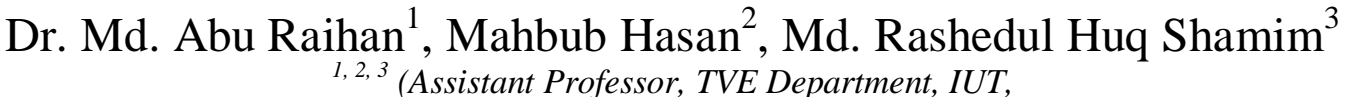

\begin{abstract}
Facebook isn't just a great way for you to find old friends or learn about what's happening this weekend; it is also an incredible learning tool. Teachers can utilize Facebook for class projects, for enhancing communication, and for engaging students in a manner that might not be entirely possible in traditional classroom settings. Read on to learn how you can be using Facebook in your classroom, no matter if you are a professor, student, working online, or showing up in person for class. Facebook has changed so much, and the site has even more to offer for the classroom. So we've compiled a fresh batch of ways to make Facebook work in TVET classrooms, some tried and true, and others that have evolved with Facebook. This article will provide to find a wealth of resources, assignments, and amazing uses for Facebook in any type of classroom. The objectives of the article were to: analyze the features of modern learning or 21th Century learning for TVET; find out the ways how Facebook enriched the interactivity in the TVET Classrooms; explain the usefulness and edutainment impact of Facebook in lecture, classes, and workshops; identify some important "Facebook apps, groups \& tools" to use in TVET to enhance learning; explain traditional teaching skills in TVET and show how those skills improve by Facebook; find out the ways to use Social media as edutainment avenue in TVET classrooms; demonstrate how Facebook promote the community makes for a richer learning environment; explain the usefulness of Facebook for classroom management and organization.
\end{abstract}

\section{Keywords: - Facebook, Edutainment, TVET, Affective Learning.}

\section{INTRODUCTION}

"Edutainment", the educational entertainment which referred to the combination of education and entertainment (Webster, 2013). It is some kinds of entertainment content or activities that are designed to educate as well as to entertain. The environment with a high degree of both educational and entertainment value is known as edutainment. There also exists content that is primarily educational but has incidental entertainment value. Finally, there is content that is mostly entertaining but can be seen to have some educational value also may the edutainment. It is a new avenue of learning in the field of Technical and Vocational Education and Training (TVET) where students learn the scientific and sophisticate contents. According to the pedagogic explanation, teaching-learning is more interesting and effective if it mixes with some entertainment. Here students get the chance of relaxation to makes their mind refresh for further learning. As a result, the complexity in learning become reduced and motivated them. Edutainment senses the students for affective learning. Affective learning outcomes involve attitudes, motivation, and values. The expression of these often involves statements of opinions, beliefs, or an assessment of worth (Smith \& Ragan, 1999).

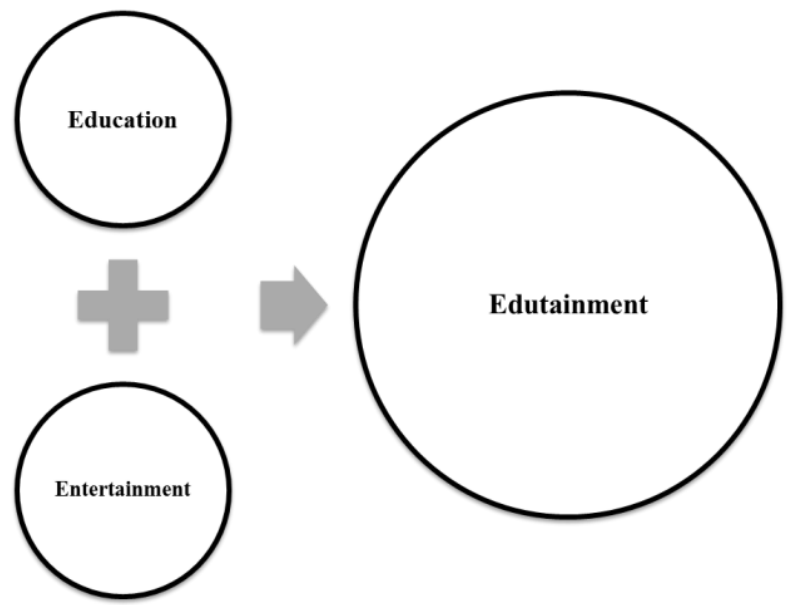

Figure: 1 what is Edutainment? 
When instructional designers consider the affective domain, they frequently think only in terms of a student's motivation to learn. As Smith and Ragan (1999) have pointed out, "any 'cognitive' or 'psychomotor' objective has some affective component to it (if at no deeper level than a willingness to sufficiently interact with learning resources to achieve the learning)" (p. 250, parentheses in original). Motivation is certainly important, as "a student's attitude toward a given course or subject area can be a contributing factor to his achievement in it" (Edwards \& Porter, 1970, p. 107).

Some researchers have found that "knowledge about a topic was often a necessary prerequisite for a positive attitude position toward the idea" (Simonson \& Maushak, 2001, p. 1010). Others suggest that "more educated people are better equipped to counter argue and hence less likely to accept or be persuaded by new information" (Ansolabehere et al., 1993, p. 151). The former theory would suggest that learners will experience more attitude change if the cognitive aspects of a lesson are presented before the affective aspects are introduced, while the latter suggests the opposite effect. The ability of a persuasive message to produce attitude change is closely linked to its strength, and "dry statistical information has less effect than vivid and concrete examples" (Zimbardo \& Leippe, 1991, p. 337). However, studies of home television viewing have shown that stories that "deal with topics about which viewers already have some knowledge tend to be remembered better" (Wetzel et al., 1994, p. 53). Presenting first the general and then the particular, first the abstract and then the concrete would seem to be sound instructional design for both cognitive and affective domains.

Since the presentation of credible and persuasive messages is a key component of attitude instruction, further exploration of what makes instruction persuasive and credible may be of use. Acceptance of a given message is "not so much about the content of the message as the cognitions - in the form of evaluative responses - that the receiver has in response to it" (Zimbardo \& Leippe, 1991, p. 150). If a given topic is of low salience or high complexity, message acceptance and attitude formation is often guided by a heuristic, most commonly source credibility. The effectiveness of a persuasive message is contingent upon the receiver's perception of the source's credibility, and credibility is a function of expertise and trustworthiness. A source or model who appears to argue against his or her self-interest is often perceived as relatively trustworthy. Simonson and Maushak (2001) have drawn on findings from a number of studies to create a series of six guidelines for effective design of attitude instruction. These are:

1) make the instruction realistic, relevant, and technically stimulating

2) present new information

3) present persuasive messages in a credible manner

4) elicit purposeful emotional involvement

5) involve the learner in planning, production or delivery of the message

6) provide post-instruction discussion or critique opportunities

Smith and Ragan (1999) focus on the behavioral aspect of attitude learning and emphasize the importance of three key instructional approaches:

1) demonstration of the desired behavior by a respected role model

2) practice of the desired behavior, often through role playing

3) reinforcement of the desired behavior

Facebook is an online social networking service. Its name comes from the colloquial name for the book given to students at the start of the academic year by some American university administrations to help students get to know one another (Eric, 2008). Facebook was founded in February 2004 by Mark Zuckerberg with his college roommates and fellow Harvard University students Eduardo Saverin, Andrew McCollum, Dustin Moskovitz and Chris Hughes (Carlson, Nicholas, 2010). As of September 2012, Facebook has over one billion active users (Facebook Tops Billion-User Mark, 2012), of which 8.7\% are fake (USA Today, 2012). According to a May 2011 Consumer Reports survey, there are 7.5 million children under 13 with accounts and 5 million under 10, violating the site's terms of service. According to the Consumer Reports (2011) Facebook (as of 2012) has about 180 petabytes of data per year and grows by over half a petabyte every 24 hours (Sharwood, Simon, 2012).

In January 2013, the countries with the most Facebook users were (Brian J. Dixon, 2013). United States with 168.8 million members; Brazil with 64.6 million members; India with 62.6 million members; Indonesia with 51.4 million members; Mexico with 40.2 million members. All of the above total 309 million members or about $38.6 \%$ of Facebook's 1 billion worldwide members (Facebook, 2012). As of March 2013, Facebook reported having 1.11 billion monthly active users, globally (Facebook, 2013). In regards to Facebook's mobile usage, per an analyst report in early 2013, there are 192 million Android users, 147 million iPhone users, 48 million iPad users and 56 million messenger users, and a total of 604 million mobile Facebook users (TechCrunch, 2013). 
Facebook is the new edutainment avenue in education/TVET for affective learning. Some of the favorite reasons to use Facebook as a meant of edutainment include: (i) Students are simply more connected: Many teachers are familiar with Blackboard and other classroom community systems, but students typically only check in when necessary, while students are often checking Facebook multiple times per day; (ii) Calendars and events are easy to share: Remind students of important dates and events right where they hang out - on Facebook; (iii) Students will learn 21st century skills: A study from the University of Minnesota discovered that social networking sites like Facebook help students practice the skills they need to be successful in the 21st century; (iv) Students want to share beyond the classroom: Facebook and other social media tools open up the possibility for students to share what they've learned not just with their fellow students, but with the world; (v) Facebook encourages collaboration rather than cliques: Everyone can speak up and work together on Facebook, where students may be held back socially in the classroom; (vi) There's an opportunity to discuss appropriate use: Set students up for success in social media by discussing appropriate ways to use it; (vii) Students can learn about social media in a safe environment: By using Facebook in the classroom, you can teach students about the safe use of social media. Facebook popularity. Active users of Facebook increased from just a million in 2004 to over 750 million in 2011 in figure-2 (Facebook Statistics, 2011).

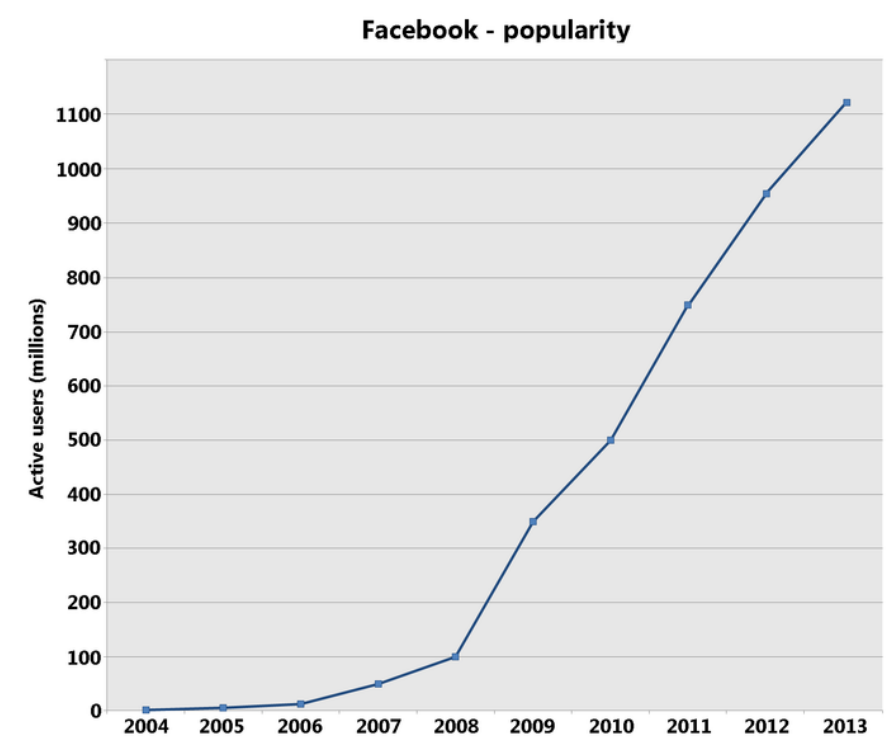

Figure: 2 Popularity of Facebook

The objectives of the article are to:

1. analyze the features of modern learning or 21th Century learning for TVET

2. find out the ways how Facebook enriched the interactivity in the TVET Classrooms

3. explain the usefulness and edutainment impact of Facebook in lecture, classes, and workshops

4. identify some important "Facebook apps, groups \& tools" to use in TVET to enhance learning

5. explain traditional teaching skills in TVET and show how those skills improve by Facebook

6. find out the ways to use Social media as edutainment avenue in TVET classrooms

7. demonstrate how Facebook promote the community makes for a richer learning environment

8. explain the usefulness of Facebook for classroom management and organization.

\section{MODERN LEARNING}

Modern learning means higher level thinking skills like analysis and evaluation are necessary just to reduce all the noise and establish the credibility of information. The higher order of learning like habits like analysis, synthesis, and evaluation are essential for TVET from where innovation take places all around. There is also the matter of utility. Evaluating information depends as much on context and circumstance as it does the nature of the data itself (TeachThought, 2013). At, we constantly wrestle with two big questions: How do people learn, and how can they do it better in a constantly evolving context? According to (TeachThought, 2013) overall the diagram offers a nice framework for the concept not of 21 st century learning, but 21 st century pedagogy by focusing on several core components of modern learning: metacognition (reflection), critical thinking, technology, and project-based learning. In pursuit, the theme of " 21 st century learning" often surfaces, a popular label that, while perhaps click, still seems to be necessary as we iterate learning models, fold in digital media resources, and incorporate constantly changing technology to an already chaotic event (i.e., learning). 
The label of "21st Century Learning" in TVET is still vague, and is an idea that have given by TeachThought (2013) can be used like to take a swing at as often as possible, including: (i) weighing the magic of technology with its incredible cost and complexity; (ii) underscoring the potential for well thought-out instructional design; (iii) considering the considerable potential of social media platforms like Facebook against its apparent divergence from academic learning.

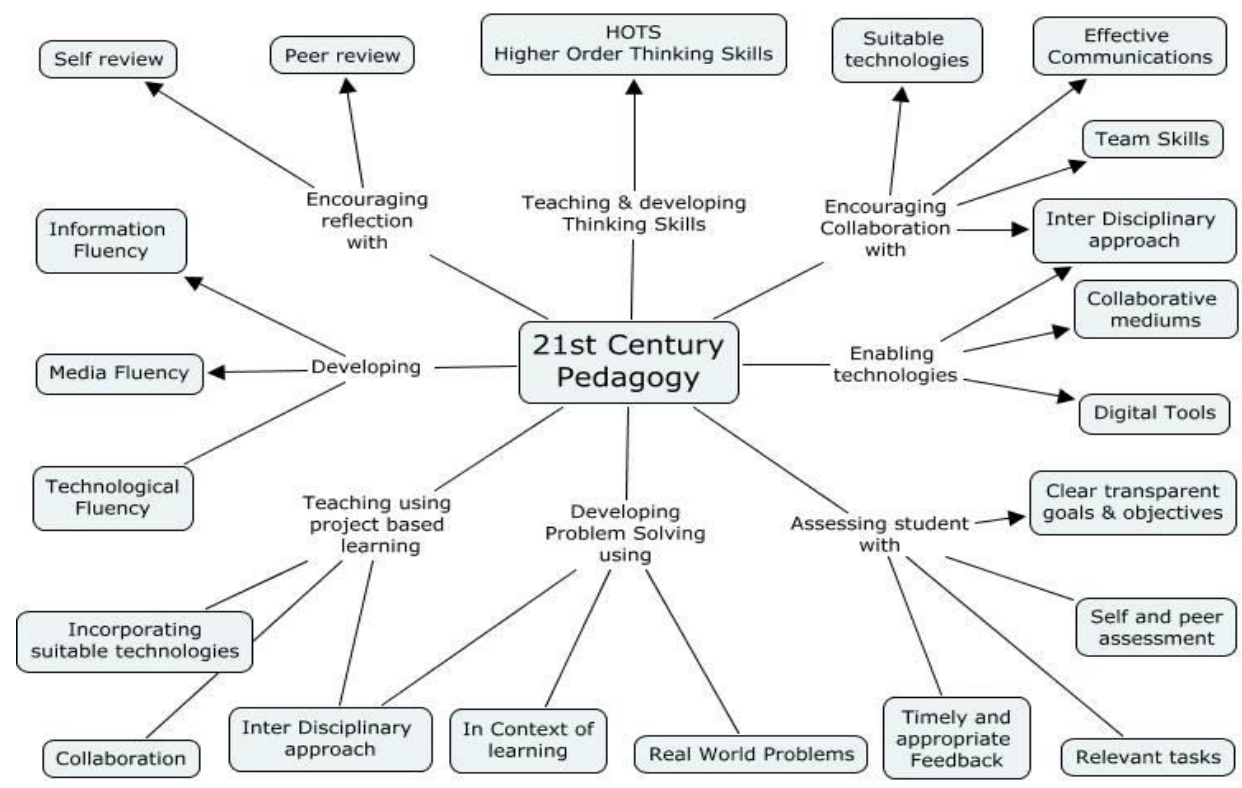

Figure: 3 Modern Learning

\section{Channels \& Characteristics of 21st Century Learning for TVET:}

"Learning channels" refer to the unique pathways students most naturally-and powerfully-use to seek understanding. These can be technology-based, but they don't necessarily have to be. And while the idea of a channel connotes content "e.g., a television or YouTube channel), this is less about content and more about how people learn. There have 6 channels for 21st century learning which can be used for the learner in TVET: (i) Dialogic Response: Learning is a conversation-whether personal, local, and direct, or more general, global, and digitally-based; (ii) Community Interaction: Communities-including local physical communities, and digital, niche communities-nurture relationships and frame content; (iii) Abstraction \& Creativity: Creativity isn't just art and whimsy, but the overlap between the macro thinking and micro details to solve the challenges of daily living; (iv) Media Literacy: Digital media evolves constantly. This makes not simply "keeping up," but grasping the nuance of platform critical; (v) Play: This is the opposite of compliant response to teacher-centered environments. It is a kind of edutainment approach; in play, learners freely experiment, show ambition, follow curiosity, and take risks to create, design, evolve, and connect in ways that are otherwise impossible under compulsion; (vi) Self-Directed Learning: Play is a big part of self-directed learning, but more broadly can include academic response, project-based learning, game-based learning, and other "school-like" learning forms while students hold themselves and one another accountable to their own criteria of quality (TeachThought, 2013).

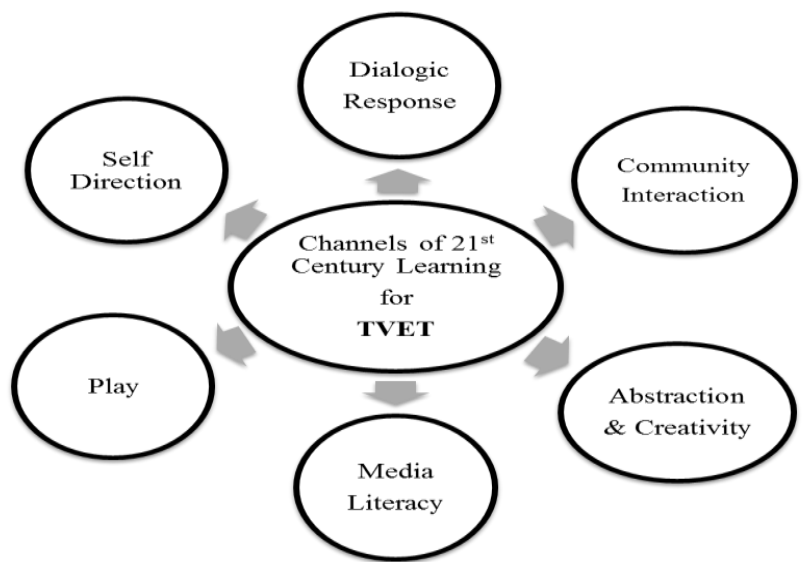

Figure: 4 Channels for 21th Century Learning 
TeachThought (2013) has mentioned nine important characteristics of 21st century learning: (i) Learner-centered ; (ii) Media-driven (this doesn't have to mean digital media); (iii) Personalized; (iv) Transferby-Design; (v) Visibly Relevant; (vi) Data-Rich; (vii)Adaptable; (viii) Interdependent; and (ix) Diverse.

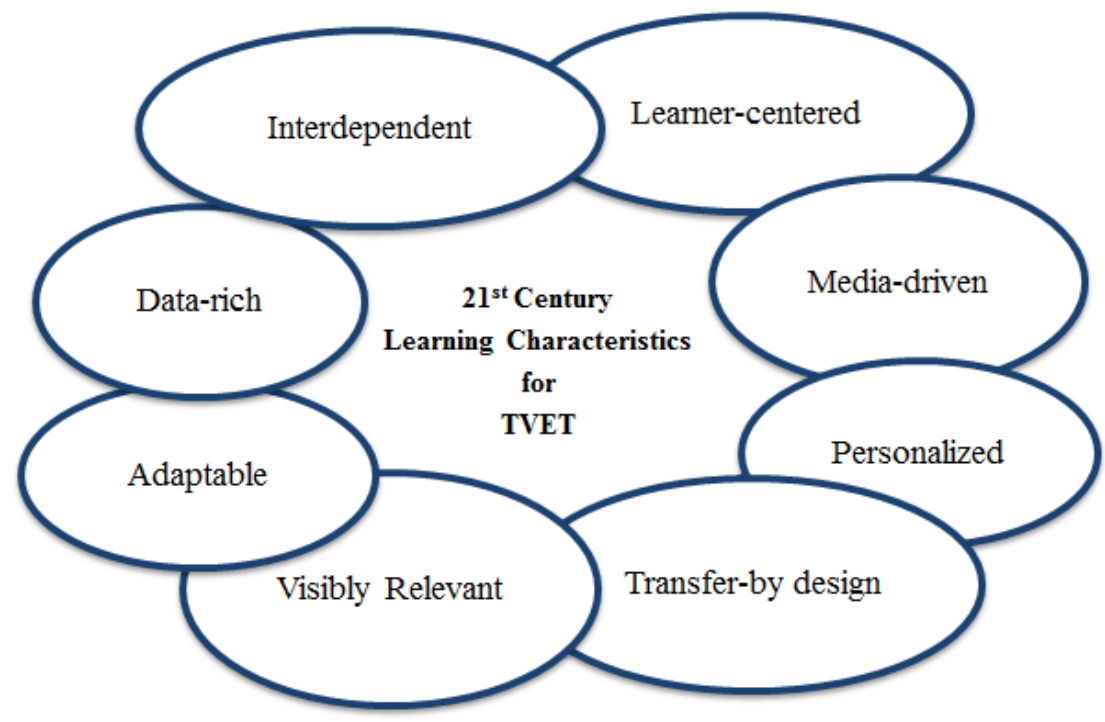

Figure: 5 Characteristics of 21 th Century Learning

\section{WAYS TO ENRICH THE INTERACTIVITY IN THE TVET CLASSROOMS}

Facebook, the attractive social networking systems enhance the interactivity in the class of TVET. (i) Bring the world to the teacher: a single networked computer empowers the teacher to use innovative resources to enhance the curriculum and save time and energy; (ii) Equip the teacher to bring the world to the students: By making a projection device available to teachers, the electronic content can be delivered directly to the students; (iii) Involve every student in their own education: By using a response system, every student is turned into an active participant on every lesson and the instant feedback enables teachers to better focus their instruction. Research has shown that the Classroom Performance System (CPS) by e-Instruction contributes to improved student achievement; (iv) Add appropriate content: By adding easy-to-use, high quality, standardaligned content, teachers can save time in preparing instruction and assessments. There are quite a few quality products available, including e-Instruction's ExamView content, which is included with your text book adoptions and can also be purchased separately. ExamView offers professionally developed, standard-aligned content that can be delivered on paper, with scan sheets, with CPS, or on the network; (v) Train teachers to use their resources. By training teachers how to apply tested teaching principles with the power of these classroom tools, the teachers become more effective while saving time and energy (Facebook, 2010).

Eight real ways (Lisa Nielsen, 2013) Facebook enriched the classrooms: (i) Providing parents and families a window to the classroom: About four times a day, student reporters update their Facebook page on something interesting that has occurred in the classroom and the teacher often comments on these updates with suggestions of things families can talk with students about at home. Additionally, families can comment right on the class page, providing advice, inspiration, and expertise to the student; (ii) Celebrating student work: The class teacher can easily share student work by taking pictures of it and placing it into albums around the unit of study. Families can comment on the work of their students and under the supervision of their parent's or teacher they can comment on one another's work too; (iii) Sharing events and announcements: The events section made it very easy to share celebrations, upcoming events and other activities with parents and families. It also allowed those invited to see who else were coming, and comment, and plan and converse. Another great use is for field trips. Organize the trips here. Know which parents can attend. Have conversations about how they can support the class during the trip; (iv) Using Facebook Notes as an Easy Way to Update Parents and Families: Facebook Notes provide a terrific way to update parents and families of important notifications in the classroom. It is very easy to share a new school or class policy. It can be tagged many parents so they get a notification in their email account and they can comment sharing thoughts, ideas, and questions; (v) Using Facebook Notes for Students to Share Writing: Next year plans to use the "notes" feature for students to publish their work. It might consider having tagged classmates, students from other classes, and/or parents comment on one another's work and give some valuable authentic feedback by "liking" work with which they really connected; (vi) Having Private Communication with Parents and Families: Ms. Schoening (Lisa Nielsen, 2013) discovered that for many Facebook was the most effective way to communicate with student's parents was Facebook. Many parents 
found this a great way to communicate and enjoyed that they didn't have to log on to something else to connect with the teacher, students or classroom. Sometimes it was the teacher communicating, but other times, it was the student who had an important message they wanted to share with a parent, like, ; (vii) Use Videos to Share Tips, Advice, and Lessons to Parents and Students: It is excited to begin using video on Facebook to extend learning and connection beyond the classroom. How do you move your child from a beginning level reader to intermediate? How can you extend science learning at home? Ms. Schoening (Lisa Nielsen, 2013) can make a video to share with parents and students that they can view together at home. Another great idea is to give students the video camera and let them video tape during a field trip. Parents, who couldn't join the class, can still see what they did; (viii) Connecting with Other Classes: The word began spreading and other teachers wanted to follow suit. You can help other teachers in your district get going, and those classes became friends. As a result of this collaborations could now easily occur across schools and classes.

\section{USEFULNESS AND EDUTAINMENT IMPACT OF FACEBOOK IN LECTURE, CLASSES, AND WORKSHOPS}

"Inside the classroom" does mean letting students use laptops and other mobile devices in the lecture hall or classroom, which may be something that many professors, teachers or academics are not used to or even willing to allow. If however, it is the institution's policy not to allow this (and can't be changed), then Twitter or Facebook can still be used "outside the classroom" for pre-, post- and in between class activities to add value to the class itself. Also some posting notes can be posted after the class, for those who missed the class; continuing the discussion, especially if out of time during class, as well as keeping the students/learners communicating with one another, dealing with students' individual questions accounts, sharing links to relevant resources and websites that pertain to the lesson. Moreover, students share their experiences of what they have done and are doing and sending out reminders about upcoming tests, project due dates, or any course/class-related news.

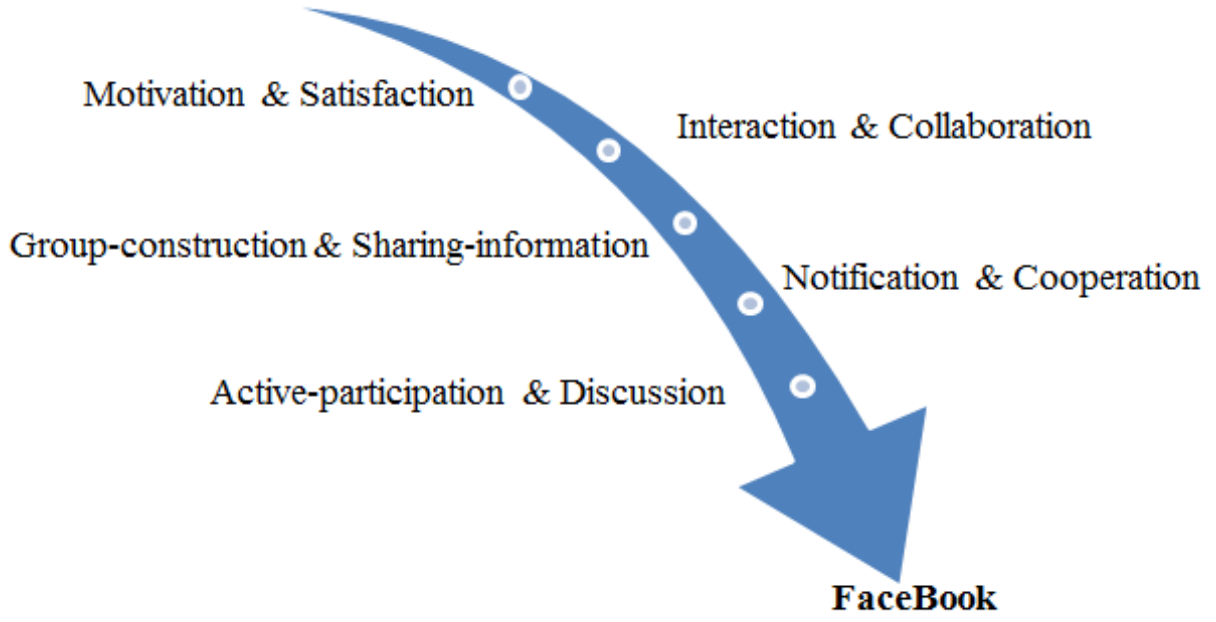

Figure: 5 Edutainment impacts of Facebook

Some edutainment impacts of Facebook have designed by the authors of this article which have shown in figure-5. In fact, Facebook increases student motivation, satisfaction, and classroom climate and studentfaculty relationship (O'Sullivan, Hunt and Lippert, 2004). Facebook has some positive impacts on studentsteacher communication, affective learning, and teacher credibility. Facebook is viewed as potentially beneficial for interaction, collaboration, information and resource sharing (Mazman and Usluel, 2010). Active participation and discussion by chatting of the students indicated that the Facebook group has the potential to be used as an edutainment tool. Important notice, lecture materials, announcement related to exam, reminder etc. may pin on the wall of the Facebook effectively. Facebook can provide a very comprehensive social environment for a class or course. It might be a good idea to set up a Facebook page for students' role as a teachers, trainer, instructor etc., if you want to keep your personal and professional life separate. You can then use this to provide information to your students - although, of course, anyone can become a fan of the page. If you want something more private, for each class or course you could set up a separate private Facebook group, which only the members of course or class can join.

\section{FACEBOOK APPS, GROUPS \& TOOLS}

There are also a large number of Facebook apps using for the teacher or educator: (i) Webinaria Screencast Recorder: Record your desktop screen movements, voice narration, webcam and post on Facebook. Create screencast demos, tutorials or record video presentations for sharing with friends; (ii) SlideShare - Share 
presentations, photos, and other great resources through the Facebook Slideshare app. If you have a slideshare account, you can import your SlideShare.net presentations into Facebook and sync them; (iii) Courses: Add your courses and activities manage and share your weekly schedule, create class discussions. This app will make managing your courses on Facebook and beyond an easier job to do. Upload and share files (iv) Udutu Teach allows you to import courses from myUdutu, manage which people can take your courses, and track the learners' progress; (v) Quiz Creator - make your own quiz app. There are also a number of Facebook apps that can be used for creating polls: (vi) Poll - Create polls for your Facebook pages and Profile pages. Ask your friends or fans questions you want or create contests for your fans thanks to Polls! Very simple and easy to use. You can also add pictures, videos or links into your polls; (vii) Questions and Polls - Want to ask your friends a question? Create multiple polls on your profile - friends can pick an existing choice, or add their own free-form answer! Users get the best of both Polls and free-form Questions. These Facebook resources can help when it comes to sharing documents, college resources, books, and more; (viii) CiteMe: Ask students to use the CiteMe app on Facebook so that they can create properly formatted citations; (ix) Booktag: Share books and ask students to comment on them with the Booktag Facebook app; (x) Acceptly: Help guide students in getting accepted to college by using the Acceptly Facebook app in class; (xi) Calendar: Make sure everyone is on the same page by sharing your class calendar through this app; (xii) Knighthood: Promote reading skills with this game app on Facebook; (xiii) Mathematical Formulas: Math teachers can take advantage of this app, sharing formulas and solutions with students on Facebook; (xiv) Used Text Books: Students can get connected with a Facebook marketplace for books through the Used Text Books group; (xv)Webinairia: Use Facebook to create and host screencasts for your classroom and beyond; (xvi) JSTOR Search: Your classroom can use the JSTOR Search app on Facebook to find useful scholarly articles and research; (xvii)Homework Help: If students are stuck on a problem, they can find assistance in the Homework Help Facebook group; (xviii) Word of the Day: Use apps like Word of the Day, This Day in History, and more to create small but fun nuggets of learning on a regular basis; (xix) Zoho Online Office: Make Facebook a source for documents with Zoho, which allows you to share and even collaborate on documents within Facebook; (xx) Notely: Get all of your classroom documents and notes organized with the help of this Facebook app for education and beyond; (xxi) Language Exchange: Help your students get connected with foreign language practice through the Language Exchange app; (xxii)Typing Test: Help students build their typing skills right inside Facebook using the Typing Test app; (xxiii) Quiz Monster: Host online quizzes through Facebook with the Quiz Monster app; (xxiii) Study Groups: This app was made to create the perfect environment for study groups to connect and collaborate on Facebook; (xxiv) Notecentric: Encourage students to take and share notes on Facebook with the Notecentric app; (xxv)WorldCat: Do research, share sources, and more within Facebook with the help of the WorldCat app; (xxvi)Hey Math! Challenge: Point students to this Facebook math app to get help understanding difficult math concepts; (xxvii) Flashcardlet: Using Flashcardlet, you can create your own flash cards that students can study on Facebook.

\section{HOW TO IMPROVE THE TRADITIONAL TEACHING SKILLS IN TVET BY FACEBOOK}

Does the TVET teacher possess modern teaching skills? As with most professions today, there are rapid developments in teaching that are being driven by social and technological changes. Keeping up to date with these developments within education will pay dividends with improved teaching skills. The skills needed to be a great teacher have now changed; modern teachers need to be competent in many new skill sets that were unknown to their predecessors. ExamTime, (2013) has given the 10 skills for the modern teachers.

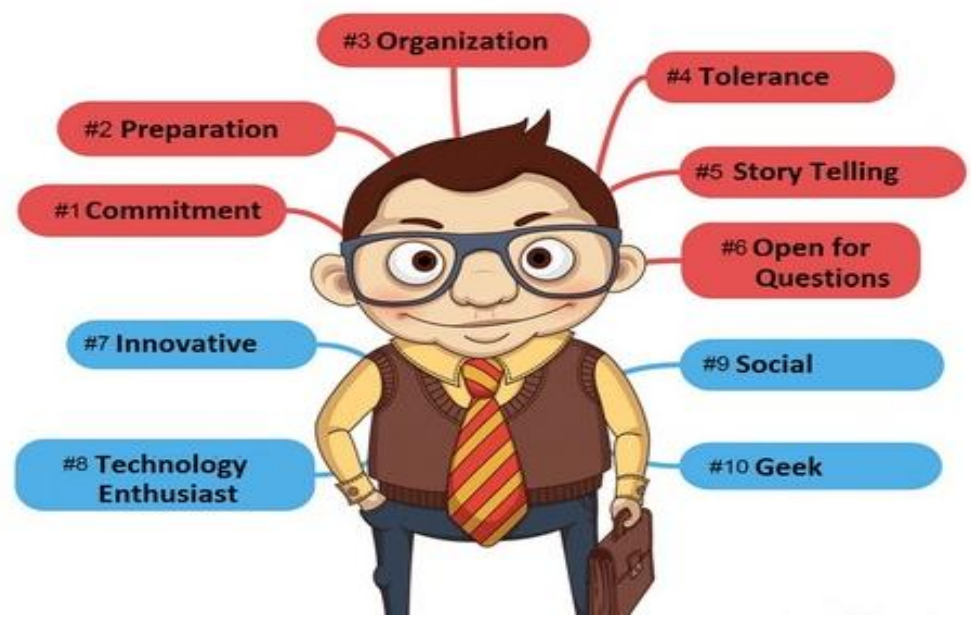

Figure: 610 Skills for Modern Teacher 


\section{Traditional Teaching Skills:}

These first 6 teaching skills (in red in the image) are not new, but their importance has increased significantly for the modern teacher. (i) Commitment: It is essential that teachers are committed to their work and to the education of young people. The responsibility that lies in the hands of a teacher is huge, so a modern teacher must always be aware of this and be truly engaged in their profession; (ii) Preparation: There used be a time when the right temperament enabled you to become a teacher. Nowadays it's imminent on impossible to find a teacher without formal academic training. This requirement is increasing as education levels improve in society. The better prepared you are as a teacher, the more effective you'll be, so you should pursue you studies with this ethos in mind; (iii) Organization: Good organization and the planning of a course in advance are key factors for success. It is very important that a teacher organizes the lesson properly and allocates the time to cover it in its entirety; (iv) Tolerance: In an increasingly diverse and multicultural society, it is necessary for teachers to manage any prejudices they may have and to treat all their students equally without showing favoritism. It's a very important teaching skill not to impose your world view on your students; instead you should openly discuss topics and let students decide for themselves; (v) Story Telling: One of the best ways to teach and transfer ideas is through stories. The best teachers have used this method in their classes for centuries. Teaching a lesson by incorporating story-telling techniques is a fantastic teaching skill to develop at any time. It engaged class is the best way to increase participation and collaboration; (vi) Open to Questions: Having discussions and collaborating in class are essential for encouraging students and implementing new teaching techniques. Teachers must be open to answering their students' questions. Modern teachers truly listen to their students questions and answer them honestly, not just with a cursory or textbook response. It may sometimes occur that you don't know the answer to a question or you don't have the time! If this happens, don't waffle or brush the question off, just explain that you will look in to it and get back to the student with a proper answer later.

\section{New Teaching Skills:}

These new teaching skills complement the more traditional ones. These skills are associated with new technologies (in blue in the image). Incorporating these into your teaching repertoire will ensure you become a modern teacher. The traditional skills can be improved by the new teaching skills if it integrates with social networking. Those are; (vii) Innovative: The modern teacher must be willing to innovate and try new things, both teaching skills and educational apps, ICT tools and electronic devices. The modern teacher must be an "early adopter"; (viii) Tech Enthusiast: The modern teacher must not only be innovative but also be willing to explore new technologies. Whether it is iPads, apps or personal learning environments, modern teachers should be in constant search of new ICT solutions to implement in their classrooms; (ix) Social : One of the traditional teaching skills was to be open to questions. The modern teacher should lead the conversation to social networks to explore possibilities outside of the class itself. We recommend "Twitter / Facebook in the Classroom: Ideas for teachers" to explore this idea in more depth; (x) Geek: It means, this in the best sense of the word. The internet is the greatest source of knowledge that humanity has ever known, so to be a modern teacher you must be a curious person and incorporate this resource at every available option.

\section{WAYS TO USE SOCIAL MEDIA AS EDUTAINMENT AVENUE IN TVET CLASSROOMS}

Why edutainment approach is needed for education/TVET? This is a vital question. Any teachinglearning process drives by the information or the resources. The resource materials are as if the fuel of the learning process. The main strength of Facebook is the arrangement of the adequately of learning resources. These resources are responsible to shape the affective domain of the learners. Some common resources on Facebook are: (i) Ask for information: Instead of trusting Wikipedia, asks the crowd on Facebook. One kindergarten teacher asked parents to research seeds and got great information about the largest seed in the world according to the Guinness Book of World Records; (ii) Attend remote lectures: Using Facebook, it can be tune into remote lectures and presentations from around the world; (iii) Museums and more: Help your students follow along with local and international museums, art galleries, exhibits, and more for enriched learning on Facebook; (iv) Firsthand research: Students can connect with family members for genealogy assignments, discuss issues with local celebrities and more through Facebook; (v) Follow politicians: If your class is studying the current election, use Facebook to follow politicians on the local, state, and national scale. You can even ask students to interact with the candidates, posting questions and getting feedback; (vi) Learning games: Plenty of games are on Facebook, and many of them are actually educational. Adopt Facebook crosswords, math games, and more as a reward in your classroom; (vii) Public polling: Students can research and poll friends and family members by simply asking questions on Facebook; (viii) Applications: Flashcards, Courses, and more offer easy ways to adopt and create learning tools in the classroom (Teachthought, 2013). 


\section{Ways to Use Social Media in the Classroom:}

(i) Make literature real: Have students create a Facebook page for a character from literature you are studying like this class did; (ii) Follow famous people: Many famous people are on Twitter. Have students follow someone related to what you are studying; (iii)Twitter treasure hunt: Use GPS treasure hunting to send students in search of educational clues as one teacher did; (iv) Learn probability: This elementary teacher uses Twitter to teach the concept of probability; (v) Connect with other classrooms: Collaborate with another classroom, no matter where they are in the world, to expand learning opportunities; (vi) Recent public updates: The recent public updates on Twitter shows the most recent posts from all users and is a great tool to use when studying current events; (vii) Field trips: Use Skype to bring the field trip into the classroom when it is difficult or impossible for students to go to the source; (viii) Conference with parents: Stay connected with parents through social media to communicate their child's progress (OnlineUniversities, 2013).

\section{Ways Students Can Use Social Media:}

From practicing a foreign language to finding scientific research, these tips will have students using social media to enhance their education. (i) Find scientific research papers: Check out the Tweprints project that collects abstracts on any scientific paper archived mentioned on Twitter; (ii) Tweet famous conversations: Have students tweet imagined conversations between famous literary figures; (iii) Attend lectures remotely: Have students attend a lecture or presentation at another campus via streaming; (iv) Practice a language: If students are learning a foreign language, they can practice with native speakers through groups on Facebook or by finding native speakers on Twitter or Skype; (v) Watch citizen journalism in action: World events unfold immediately on Twitter, so invite students to follow citizen journalism along with the mainstream news; (vi) Track a word or phrase: Track a word or phrase to see how it is being used by others to learn the nuances of language; (vii) Learn personal responsibility: Students can learn personal responsibility when they find out about how to use social media sites responsibly (OnlineUniversities, 2013).

\section{Ways Instructors Can Use Social Media:}

No matter what level class you teach, there are ways for you as an instructor to use social media for the classroom, your career, and beyond. (i) Offer a class: Offer a class featuring social media such as featuring Twitter; (ii) Collaborate with other professionals: Learn from and share with other instructors around the world by sharing ideas, tips, and techniques through Twitter or Facebook; (iii) Use Twitter to teach journalism: Have students use Twitter to report news in 140 characters or less to practice communicating important information succinctly; (iv) Answer questions: Be available for answering students' questions via a Facebook page or Twitter feed; (v) Prospective students: Monitor Twitter or Facebook for specific key words to connect with potential students; (vi) Conferences: Find out what's going on at professional conferences through social media; (vii) Have fun at conferences: If you are attending a conference, give BackChatter a try-a game that uses Twitter and makes attendees interactive participants; (viii) Teach Twitter/Facebook: Teach students how to use Twitter/Facebook by offering assignments; (ix)Post notes: Post class notes on Twitter/Facebook so students who missed a class can find out what they missed and instructors can refer back to any notes they left; (x) Tweet lesson plans: Teachers can tweet their lesson plans, or links to them, to keep students updated and provide inspiration for other educators; (xi) Faculty or staff forum: After you've gained experience using social media in the classroom, host a presentation for fellow instructors to share what you have learned; (xii) Live blog: When you use Twitter/Facebook to live blog a conference or lecture, you provide a transcript for others of what was discussed and keep awesome notes for yourself; (xiii) Instant feedback: Have a student tweet about your class to receive instant feedback. This is especially helpful for those teaching a large lecture class; (xiv) Take attendance: Have students tweet one thing you discussed in class as a great way of taking attendance; (xv) Test new technology: Recruit help testing new apps or other technology from social media resources; (xvi) Recruit guest speakers: Recruit guest speakers for your class from social media contact such as colleague or past students (OnlineUniversities, 2013).

Social media outlets like Facebook and Twitter offer a great way to enhance communication among students and teachers. (i) Post homework: Teachers can post homework assignments through Facebook to provide easy access for students and to put the assignment and due date in writing; (ii) Classmate connections: No matter the size of your class, having all the students on a social media outlet brings them all together; (iii) Provide direct communication with instructors: When teachers and students can easily contact each (as through Facebook or Twitter), they create better working relationships; (iv) Send messages and updates: From unexpected absences to reminders of upcoming tests, Facebook and Twitter both offer great ways to stay updated on any occurrences; (v) Brainstorm: One benefit of social media is the ability to write down thoughts any time they occur. Encouraging students to brainstorm on class topics outside class time provides more opportunities for sharing great thoughts; (vi) Schedule events: Easily schedule events for the entire class using 
Facebook or by posting on Twitter; (vii) Create groups: You can create groups for entire classes or for smaller subsets such as study groups on Facebook and Twitter; (viii) Help shy students: Shy students who may feel uncomfortable approaching their teacher in person can use social media as a way to communicate; (ix) Share interesting websites: Both students and instructors can share interesting websites related to class topics via social media; (x) Multimedia: Share multimedia content easily with the entire class on Facebook; (xi) Asynchronous class conversation: When something relevant to class happens during a time when class isn't in session, students can discuss it through social media (OnlineUniversities, 2013).

Assign class projects using social media to have students participate in dynamic learning opportunities. (i) Share book reviews: Students can post their book reviews for the instructor to grade and other students to read on a class Facebook page; (ii) Play Knighthood: This Facebook game promotes reading skills and has been used in at least one ESL class; (iii) Poll the class: Use polls as an interactive teaching tool in class using the Poll app for Facebook or PollDaddy for Twitter; (iii) Create a news feed: Have a journalism class report news via Twitter a feed or the Facebook status update; (iv) Follow news stories: Use groups like World News Now on Facebook that provide video clips of world news; (v) Do community service: If your class is communityminded, organize a community service class; (vi) Create stories: Have students create a story, one by one, using only one Twitter post of 140 characters or less and one student at a time; (vii) Post student projects: Set up a Facebook page to showcase student projects; (viii) Author visits: Use Skype to set up author visits that allow students to interact with the author; (ix) Interviews: Have students conduct interviews with teachers, school staff, or other students and share the interview via a Skype feed to other classrooms (OnlineUniversities, 2013).
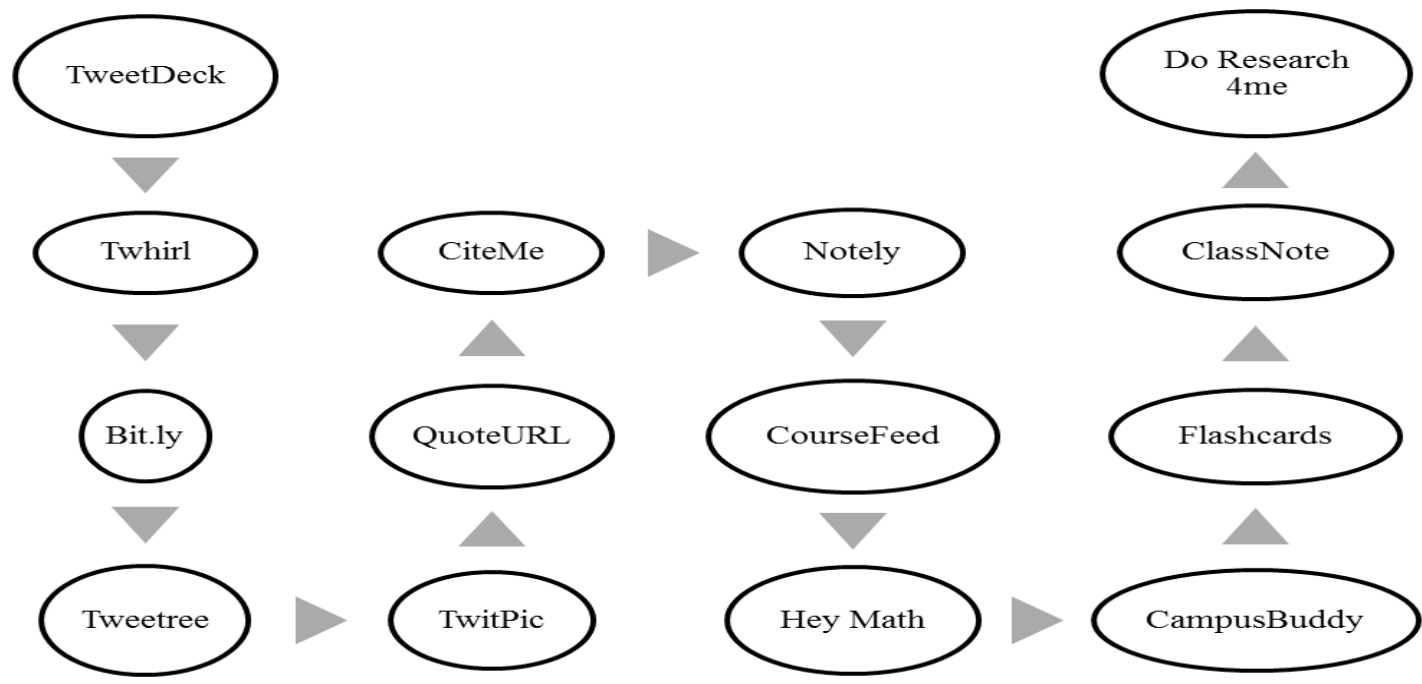

Figure: 7 Social media tools for students

\section{Some Social Media Tools for Students are shown in figure 7:}

These tools for Twitter and Facebook will provide students even more ways to use social media at school. (i) TweetDeck: Students can use this tool to help organize their Twitter feeds. It also provides an excellent way to tweet from their iPhones; (ii) Twhirl: Twhirl is another helpful tool for managing Twitter and includes features such as URL shortening and new message notifications; (iii) bit.ly: Posting long links eats up the 140 characters allotted on Twitter, so shorten URLs with this tool; (iv) Tweetree: Twitter can get confusing with several conversations going on at once, so use this tool to group conversations together; (v) TwitPic: Share photos on Twitter; (vi) QuoteURL: If students want to put different tweets all on one page (for summarizing a project, for example), then this is the tool to use; (vi) CiteMe: This Facebook app provides properly formatted citations according to APA, Chicago, Harvard, MLA, or Turabian; (vii) Notely: Notely users who are on Facebook can organize assignments, classes, notes, and more with this app; (viii) CourseFeed: Add this app to Facebook to find online classes or follow your current class, (ix) DoResearch4Me: Steer students away from finding information on Wikipedia with this Facebook app that finds information online from other sources; (x) Hey Math! Challenge: This Facebook app provides Flash movies that clearly explain difficult math concepts; (xi) CampusBuddy: Find students attending your school with this Facebook app; (xii) Flashcards: Use this app to create flashcards on any subject right on Facebook; (xiii) Class Notes: Take a photo of teacher's notes or your own notes and post them so others in your class can see.

Sharing: Give students, parents, and your community something of value by sharing knowledge and resources through the power of Facebook. (i) Import your class blog to Facebook: If your class maintains a blog, be sure to have it shared on Facebook; (ii) Ask parents to get involved: Parents can follow along as kids 
post their projects, and even highlight any insightful resources they may know about; (iii) Pet day can get a little less scary: Students with pets that are not quite appropriate for school (like huge pythons or newborn kittens) can still participate, sharing photos of their beloved friend at home; (iv) Archived videos: Important lectures, slides, and more can be shared and saved on Facebook; (v) Document class trips: Your class may share the tasks of taking photos, notes, and more to share in a Facebook report on the activity; (vi) Highlighting vocabulary: An easy and quick way to fit vocabulary review into study time is posting words and definitions on Facebook; (vii) Make graphs out of parent data: Ask parents about household habits, favorite animals, and more, creating graphs in your classroom that you can share on Facebook; (viii) Explore Questions: Facebook offers a Questions app, which is clearly useful for the classroom and allows teachers to ask questions about photos, topics, and more with responses from students; (ix) Archive discussions: Facebook is a great place to link to and archive classroom slides, discussions, and more that students can reference if they missed class or need to review; (x) Posting educational content: Teachers can post educational videos and links for concepts that are currently being discussed in class.

\section{FACEBOOK PROMOTE THE COMMUNITY MAKES FOR A RICHER LEARNING ENVIRONMENT}

Working together and promoting a sense of community makes for a richer learning environment. Find out ways to do just that with social media. (i) Promote community: Students sharing personal information through social media create a sense of community, which leads to more open communication and better learning; (ii) Online communities: Social media can connect online communities such as classrooms or teachers' groups to help create a larger community; (iii) Interpersonal understanding: Getting to know small bits of others over time, as happens through social media, provides a greater picture of who those people are and develops a deeper sense of understanding for more openness and sharing in the classroom; (iv) Use backchannel: "Backchannel" refers to the conversation occurring secondary to the main lecture or presentation via social media. Use backchannel to enhance both teaching and learning; (v) Blog: Create a community blog and share it on Facebook to tell what your class is learning and doing; (vi) Guest lecturers: Have guest lecturers visit the classroom through Skype if they are located too far away to come in person; (vii) Collaboration: By definition, social media outlets are designed to promote social interchange, so harness that capability to have students work on activities together through social media, (viii) Stay relevant: Schools moving from an old, skill-centered approach to one that embraces connectivity through social media will provide a better learning environment for students; (ix) Collaborate with professionals: it is easy to collaborate with the professionals via Skype; (x) Make changes: When a book was not allowed to be taught in one school, students connected with the author of the book and collaborated on how to approach the school board with their case; (xi) Inclusion: Students who may have to be out of the classroom due to special needs or illness can be connected to the class remotely and stay a part of the community (OnlineUniversities, 2013). The richer learning environment can be created through collaboration and discussion to accomplish the academic and administrative tasks in TVET organizations.

\section{Collaboration \& Discussion:}

Students, educational professionals, and even parents can get together for collaboration and discussion through Facebook. (i) Ask for feedback on assignments and activities: If you're not sure of a new assignment or activity that you'd like to introduce in your classroom, ask students what they think on Facebook; (ii) Writing workshops: Facebook's collaborative nature makes it easy for students to participate in writing workshops with peer review and instructor oversight; (iii) Set up a Facebook backchannel: For courses that are simply too large to allow every student to participate in the discussion, encourage students to communicate through a Facebook discussion wall that operates during class time; (iv) Practice foreign language with native speakers: Use Facebook to connect your classroom with speakers around the world, and get a chance to improve their foreign language skills; (v) Encourage online participation: Bring quiet students out of their shell by asking them to participate in Facebook discussions; (vi) Create study groups: Allow study groups and group projects to easily connect with each other within their own Facebook groups; (vii) Take classroom polls: Need to gather classroom opinions on snack time, movie Friday, or the next book to read? Take a poll on Facebook!; (viii) Get connected with guest speakers: Use Facebook to track down old students or professionals that would make for great guest speakers in your classroom; (ix) Students can discuss work through Notes: On Facebook Notes, students can publish their work, tag classmates, and get feedback on what they've written; (x) Connect with classes around the world: Whether it's a class in your school, or a class on another continent, Facebook offers a great way to get connected with other students; (xi) Discuss classroom ideas with other teachers: Facebook is great for connecting not just classes, but teachers with helpful ides; (xii)Homework help: It may be awkward for some students to call up a classmate and ask for help on a homework problem, but posting on a class Facebook 
wall is less intrusive, and teachers can get involved as well; (xiii) Stay in touch with old students: Keep in touch with old students and find out what's been valuable to them years down the road.

\section{FACEBOOK HELPS THE TVET PEOPLES FOR CLASSROOM MANAGEMENT AND ORGANIZATION}

Classroom Management \& Organization: These ideas offer great ways to enrich the classroom with personal connection, reminders, and tools for organization. (i) Post events: Get your classroom event on your students' calendars by creating a Facebook event. This can be used for everything from exam dates to afterschool mixers; (ii) Organize different classes into groups: If you teach any number of different courses, keep things organized by asking students to join appropriate groups for their class; (iii) Celebrate birthdays: Use Facebook as a tool for remembering and pointing out birthdays within your classroom community; (iv) Familiarize yourself with students: In large classes, it can sometimes be hard to remember each and every student. Facebook makes it a little easier to connect faces and personalities with names; (v) Get a record that students read what you're writing: Emails get ignored, but you can ask students to "Like" important updates so that you'll know they got the message; (vi) Share positive updates: When a certain class or group does particularly well, be sure to point it out with a Facebook status message; (vii) Save paper: Instead of handing out permission slips and flyers, post them to Facebook and allow parents to download and print them at home; (viii) Continue discussions on Facebook: If you're finding that an interesting discussion is taking up too much classroom time, ask students to simply continue the discussion on Facebook and move on; (ix) Share last minute updates: Let students know if school is closed due to snow, if you'll be absent, and more on Facebook; (x) Investigate "dog ate my homework" claims: One professor busted a student who had lied to her about losing Internet access (and was thus unable to work on her paper), pointing out that she was somehow able to connect because she made several Facebook updates during that same time; (xi) Maintain a classroom map: Share a geography lesson and increase participation at the same time by asking students to share their heritage, travels, and favorite countries; (xii) Parents can learn about what kids are doing: Gone are the days when parents have to pry information out of their kids with power tools. Now, parents can get in on the classroom through Facebook, and spark conversations about projects they've actually seen already; (xiii) Ask for feedback on exams: Gauge how students think they did on exams by asking about them on Facebook, and appropriately plan how much time you'll need to grade them; (xiv) Get updates on progress: Make sure students are staying on top of their assignments by using Facebook to ask how things are coming along; (xv) Improve classroom participation: Keep students engaged by giving them something productive to do on Facebook, rather than allowing them to zone out on the social site during lectures; (xvi) Use Facebook for career guidance: Get students connected with recruiting professionals, mentors, and more through Facebook; (xvii) School fundraising: Use Facebook to promote any fundraising activities have in the classroom; (xviii) Create a Facebook page for parents: Many teachers have found that parents aren't happy with their existing method of communication, whether it's an online parent portal, or just pinning notes to backpacks. Creating a Facebook page for your class offers an excellent opportunity for parents to get involved and stay informed; (xix) Find out what students are into: Learn about their hobbies and interests, and you just might discover a way to bring what they love into the classroom; (xx) Host fun contests: Host contests on Facebook that require students to participate or attend to win, keeping kids involved in studies; (xxi) Remind students to come to class: Facebook is a great tool for reminding frequently tardy or absent students to make it on time to class; (xxii) Finding future lessons: Paying attention to discussions on your Facebook classroom page can help you discover great ideas for future lessons and assignments; (xxiii) Stay up to date on assignments: Remind students of assignments they need to be working on, upcoming due dates, and more with Facebook; (xxiv)Tag books: Tag books for students to read easily and conveniently right on Facebook, and even create resources to go along with the readings; (xxv) Clarify directions: If it's clear some students are having trouble understanding an assignment, use Facebook to post clarified directions; (xxvi) Celebrate student work: Teachers can highlight some of the best work students have done in any period of time on Facebook walls.

\section{CONCLUSION}

Without proper training, the tools of Facebook may be wasted. Professional development should include more than "where to click." Some educators seek out the ideal of a $21^{\text {st }}$ century learning environment constantly, while others prefer that we lose the phrase altogether, insisting that learning hasn't changed, and good learning looks the same whether it's the $12^{\text {th }}$ or $21^{\text {st }}$ century.

\section{ACKNOWLEDGEMENT}

The enormous materials have been collected from different sources of the Websites to prepare this article. All the collected materials have compiled and categorized especially to fulfill the objectives carried out by the research paper. Though, Facebook, the social networkings have been uprising issues all over yet, there 
have insufficient books to narrate the updated pros and cons on those issues. Thus, the researchers have taken the information vigorously from the Internet. It was quite awful to prepare this article without getting the recent trends, issues and horizons of Facebook as social media from the Website named (i) OnlineUniversities,(ii) Teachthought,(iii) ExamTime, and (iv)Wikipedia of Facebook. The authors of this article would like to express the gratefulness and thanks as they used the authentic information from those sites.

\section{REFERENCES}

[1] Ansolabehere, S., Behr, R. and Iyenger, S. (1993). The media game: American politics in the television age Don Mills, Ontario: Maxwell Macmillan Canada.

[2] Brian J. Dixon (2013). Helping you do your impossible; Top reasons to use Facebook in the classroom; Retrieved from the Web (November 1, 2013) http://brianjdixon.com/facebook_in_classroom

[3] Carlson, Nicholas (2010). At Last - The Full Story Of How Facebook Was Founded. Business Insider.

[4] Consumer Reports (2011). Five million Facebook users are 10 or younger. May 10, 2011. Retrieved October 15, 2013.

[5] Edwards, A.L. \& Porter, B.C. (1972). Attitude measurement. In The affective domain: A resource book for media specialists (pp. 107-126). Washington, DC: Gryphon House.

[6] Eldon, Eric (2008). 2008 Growth Puts Facebook In Better Position to Make Money. VentureBeat (San Francisco). Retrieved October 19, 2013.

[7] ExamTime (2013). ExamTime Blog Post; 10 Modern Teaching Skills; Retrieved on 9 November, 2013 from the Web https://www.examtime.com/blog/teaching-skills/

[8] Facebook (2010). Ways to enrich the interactivity in the TVET Classrooms, Retrieved on November 1, 2013 from the Web https://www.facebook.com/note.php?note_id=450684132701

[9] Facebook (2012). 43.1 Million Members of Facebook in Indonesia. February 2, 2012.

[10] Facebook (2013). Facebook Reports First Quarter 2013 Results - Facebook. Investor.fb.com (May 1, 2013). Retrieved on July 21, 2013.

[11] Facebook Statistics (2011). Facebook Statistics by country. March 3, 2012.

[12] Facebook Tops Billion-User Mark (2012). The Wall Street Journal (New York). October 4, 2012. Retrieved October 4, 2013 From the Web http://www.teachthought.com/technology/100-ways-to-usefacebook-in-education-by-category/

[13] Lisa Nielsen (2013). The Innovative Educator, Retrieved on November 7, 2013 from the Web http://theinnovativeeducator.blogspot.com/2010/07/8-real-ways-facebook-enriched-ms.html

[14] Mazman, S. G. \& Usluel, Y. K. (2010). Modeling educational usage of Facebook. Computers \& Education, 55,2.

[15] O'Sullivan, P. B., Hunt, S. K. \& Lippert, L. R. (2004). Mediated immediacy: a language of affiliation in a technological age. Journal of Language and Social Psychology, 23, 4, 464-490.

[16] OnlineUniversities (2013). 100 Inspiring Ways to Use Social Media in the Classroom, Retrieved on 11 November, 2013 from the Web http://www.onlineuniversities.com/blog/2010/05/100-inspiring-ways-touse-social-media-in-the-classroom/

[17] Sharwood, Simon (2012). Facebook warehousing 180 PETABYTES of data a year. The Register. Retrieved October 15, 2013.

[18] Simonson, M. and Maushak, N. (2001). Instructional technology and attitude change. In D. Jonassen (Ed.), Handbook of research for educational communications and technology (pp. 984-1016). Mahway, NJ: Lawrence Erlbaum Associates.

[19] Smith, P. \& Ragan, T.J. (1999). Instructional design. New York: John Wiley \& Sons.

[20] Teachthought (2013). 100 Ways To Use Facebook In Education By Category. Retrieved on 11 November, 2013 from the Web

[21] TeachThought (2013). Modern learning; A Diagram Of 21st Century Pedagogy; retrieved on 9 November 2013 from Web http://www.teachthought.com/technology/a-diagram-of-21st-centurypedagogy/

[22] TechCrunch (2013). "Facebook Mobile User Counts Revealed: 192M Android, 147M iPhone, 48M iPad, 56M Messenger, 604M total users". January 4, 2013. Retrieved November 12, 2013.

[23] USA Today (2012). Facebook: About 83 million accounts are fake. Retrieved October 4, 2013.

[24] Webster, M. (2013). Edutainment, Retrieved November 1, 2013 from Web http://www.merriamwebster.com/dictionary/edutainment

[25] Wetzel, C.D., Radtke, P.H. \& Stern, H.W. (1994). Instructional effectiveness of video media. Hillsdale, NJ: Lawrence Erlbaum Associates.

[26] Zimbardo, P.G. \& Leippe, M. R. (1991). The psychology of attitude change and social influence. New York: McGraw-Hill. 